\title{
A review on different control techniques using DSTATCOM for distribution system studies
}

\author{
K. Swetha, V. Sivachidambaranathan \\ Department of EEE, Sathyabama Institute of Science and Technology, India
}

\begin{tabular}{l}
\hline \hline Article Info \\
\hline Article history: \\
Received Sep 6, 2018 \\
Revised Nov 19, 2018 \\
Accepted Feb 15, 2019 \\
\hline Keywords: \\
AI \\
DSTATCOM \\
HEPWM \\
NFC \\
NN \\
PSPWM, \\
PWM \\
RLS \\
\hline
\end{tabular}

ABSTRACT
This paper focus on distribution system by applying different control
techniques in order to improve the performance of the system. In the
distribution system mainly concentrate on power quality issues like reactive
power control, harmonic elimination, power factor correction, etc. Because
of power quality problems voltage, current, frequency are continuously
changing in power systems. These changes will effects the performance of
power systems. Power quality problems can be compensated by placing
DSTATCOM which is connected at PCC in parallel. It is shunt connected
VSI along with the filters, with the help of DSTATCOM voltage sag, swell
and THD can be controlled. This paper presents detailed explanation about
performance and configuration of latest control techniques to control the
DSTATCOM.
Copyright $\odot 2019$ Institute of Advanced Engineering and Science.
All rights reserved.

Corresponding Author:

K. Swetha,

Department of EEE,

Sathyabama Institute of Science and Technology,

Old Mahabalipuram Rd, Kamaraj Nagar, Jeppiaar Nagar, Chennai, Tamil Nadu 600119, India.

Email: swethasathyabama@gmail.com

\section{INTRODUCTION}

Generally, Power system is combination of Generation, Transmission and Distribution of power. The main consideration is quality of power delivered to consumers [1]. In recent years usage of Power Electronic equipment and reactive power consuming loads are increased these are the main causes for the rise of power quality problems. To reduce power quality problems shunt active power filters are used, it is similar to voltage source inverter to produce reverse harmonic currents using Clark's transformation technique. This control strategy used to instantaneous reactive power theory to develop shunt active power filter for non linear loads [2]. There are many power quality problems, out of them compensation of reactive power and elimination of harmonic currents are the major problems, these are caused by non linear loads, these problems can overcome by active power filters and to control the active power filters, Phase Locked Loop (PLL) are placed major role.All equipment related to Electrical and Electronics are suffers from power quality problems when they are connected to distribution system [3]. This may leads to sudden change in current, voltage profiles which results in poor performance of equipment and power losses by using fundamental frequency based modified $\mathrm{I}_{\mathrm{d}}-\mathrm{I}_{\mathrm{q}}$ control scheme to develop reference current to control DSTATCOM, out of all the custom power devices distribution compensator is one of the most effective power device to explain the issues related to power quality [4].

A Distribution Static Compensator (DSTATCOM) is a Voltage Source Inverter (VSI)-based Power Electronic device [5]. Usually, this device is supported by short-term energy stored in a DC capacitor. Alternatively, it can also clean up the voltage of a utility bus from any unbalance and harmonic distortion. 
In power Electronics controller circuits different controll techniques used are PWM techniques, Resonant Converters, DC-DC converter circuits, Multilevel Inverter, etc. Bi-Directional Theee Phase Parallel Resonant High Frequecny AC link converter is given [6]. Two Phase Interleaved high gain DC converter using MPPT Algorithm is explain [7]. Enhancemet of Active Power Filter using SRF Theroy is given [8] Interleaved DC-DC converter technique is explained [9] Half Birdge Resonant Converter technique is explaind [10]. PI controler and Fuzzy logic controller circuits are proposed in all the above Power Electronics controller circuit for getting the desired output voltage and gain. The design is shown in Figure 1.

Advantages of DSTATCOM:

a. It compensates negative sequence currents.

b. For various types of load compensates reactive power.

c. Eliminates harmonics effectively which are caused by the non linear loads.

d. It will perform harmonic compensation and load balancing also.

e. Improves the current harmonic distortion.

f. It improves the quality of power by reducing voltage sags and fluctuations.

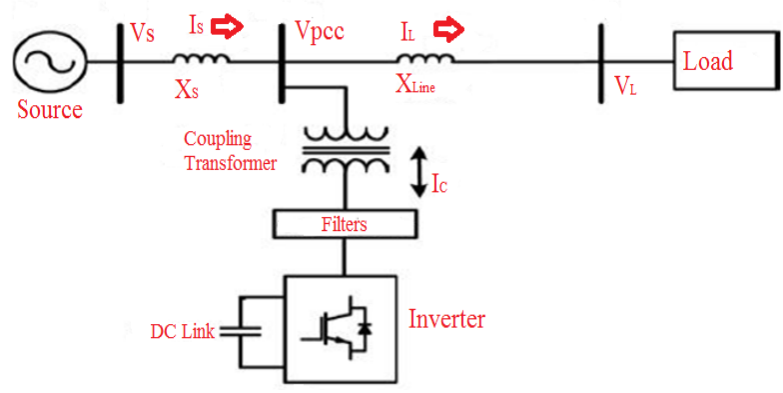

Figure 1. Power flow diagram

Consider a system having source and load after giving supply because of different types of load some unwanted quantities like Harmonics, Reactive power, voltage sage \& swells are fed back to supply side [11]-[14]. To control these unwanted parameters, a device is connected at a point of common coupling by changing the control techniques. For example consider a PI controller, this compare the given source parameters with reference parameters and generate pulses. These pulses are used to operate VSI-IGBT circuit. The control techniques compensates output parameters [15]. Thus by changing the device control technique, the unwanted parameters are controlled and the performance of the distribution system are improved, P-Q reference theory is used to develop reference currents to control DSTATCOM to improve power quality.

A Distribution static compensator is a power device which is connected in shunt configuration to decrease the problems related to power quality which includes harmonic elimination, load balancing like voltage and current related problems. In this review various control techniques for DSTATCOM are mentioned clearly.

\section{SYSTEM CONFIGURATION}

The Figure 2. shows the circuit diagram for voltage source based DSTATCOM connected to 3phase AC mains leading to the non linear loads with source impedance $Z_{s}\left(Z_{S}=R+j X_{L}\right)$ to control the DSTATCOM using self tuning filters based on different control techniques for the estimation of reference current generation [16]-[18]. Here input variables are connected at $\mathrm{PCC}$ voltages of $\left(\mathrm{V}_{\mathrm{a}}, \mathrm{V}_{\mathrm{b}}, \mathrm{V}_{\mathrm{c}}\right)$ supply current $\left(\mathrm{I}_{\mathrm{sa}}, \mathrm{I}_{\mathrm{sb}}, \mathrm{I}_{\mathrm{sc}}\right)$ load current $\left(\mathrm{I}_{\mathrm{La}}, \mathrm{I}_{\mathrm{Lb}}, \mathrm{I}_{\mathrm{Lc}}\right)$. In that interfacing inductances are connected at distribution side of voltage source $\mathrm{V}_{\mathrm{s}}$ for reduction of ripple current. Three phase DSTATCOM topology with interfacing LCL filters DSTATCOM gives sufficient reactive power demand to the load side so that only active power is generated by the source and it will delivered to the loads therefore sources remains balanced and sinusoidal, dc link capacitors are placed for neutral current compensation and also acting as power exchangers to the converters.

Int J Pow Elec \& Dri Syst, Vol. 10, No. 2, June 2019 : $813-821$ 


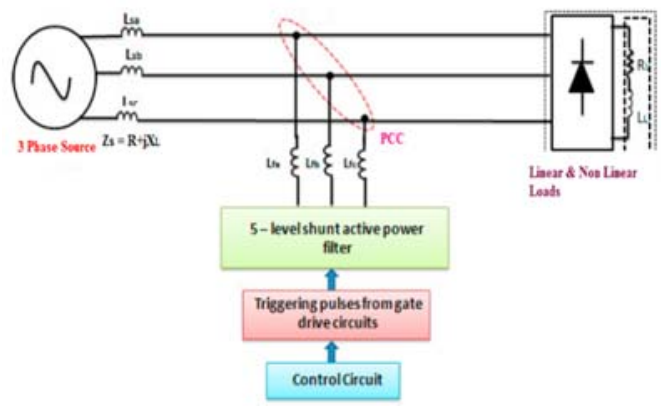

Figure 2. Voltage source based DSTATCOM

\section{DIFFERENT CONTROL TECHNIQUES}

\subsection{PSWM technique}

In 2018 A.Awalludin, C.Ltohin proposed this technique [19] for Cascaded Multilevel Converters, when the recuperating converter system produced high harmonic current, this can compensated with PSPWM. PS-PWM offered extremely low distortion in phase current. In 2017 R.Shibarani, Dr.C.Srinivasa rao, Dr.M.Vijaya kumara [20] offered PSPWM based five level shunt active power filter for power quality improvement in power system network. In this paper main objectives are hormonic elimination and power factor improvement. These can be done with the help of phase shift carrier pulse width modulation techniques along with clark transformation. Due to non linear loads, power quality problems are increasing in distribution system. In power quality problems hormonics are main consideration. In this article to reduce the hormonics by using five level cascaded multi level DSTATCOM is placed, to generate gating signals to the voltage source inverter, phase shift carrier PWM technique is used. In this technique comparision between traingular carrier signals with sinusoidal refference signals is done, to generate triggering pulsess to VSI. In this control technique cascaded 5-level inverter has been implemented based on shunt active power filter, to convert three phase source voltages $\mathrm{V}_{\mathrm{sa}}, \mathrm{V}_{\mathrm{sb}}, \mathrm{V}_{\mathrm{sc}}$ and load currents $\mathrm{I}_{\mathrm{la}}, \mathrm{I}_{\mathrm{lb}}, \mathrm{I}_{\mathrm{lc}}$ into two phase $\mathrm{V}_{\alpha}, \mathrm{V}_{\beta}$ and $\mathrm{I}_{\alpha}, \mathrm{I}_{\beta}$ can be performed by using clark transformation. The output of clark transformation is given as a input of the $\mathrm{p} \&$ $\mathrm{q}$ transformation. In this active and reactive powers are devides and passed through pass band filters therefore active and reactive powers are uptained and the reference current are determined. With the help of output of clark transformation voltage, along with the output of active and reactive powers these are given as a input to the inverce clark transformation ( $\alpha \beta$ to $\mathrm{abc})$.

The Figure 3 shows the PS-PWM Technique. These inverse Clark transformation outputs are given as inputs to the reference currents of PS-PWM. In the PSPWM produces firing pulses to power switching of VSI by using this technique in this article \%THD at source side is maintained with in IEEE 519 standards i.e 3.27 so that source current maintained balanced way that will not effect the loads which are connected at PCC.

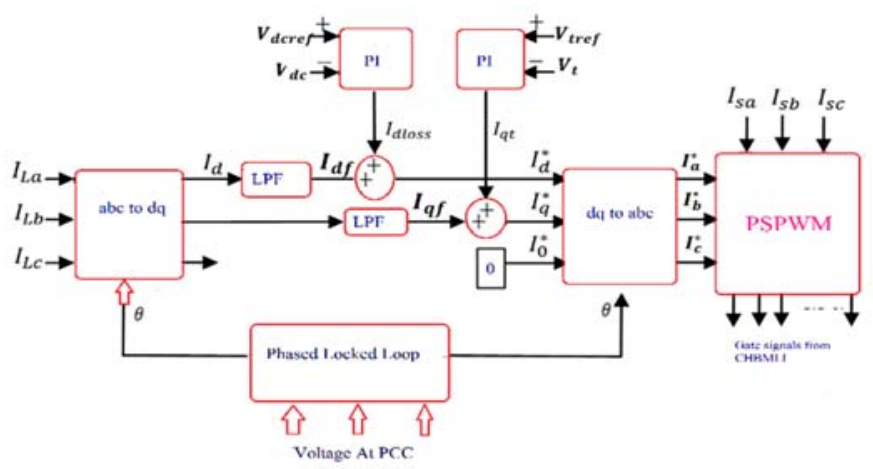

Figure 3. PS-PWM Technique 


\subsection{Harmonic elimination PWM technique}

In 2017Ahmed Majed, Zainal Salam, Abdual Moeed Amjad [21] developed Harmonic elimination PWM based direct control for 23 level multilevel distribution STATCOM using differential evolution algorithm.

In this article authors explained about harmonic elimination PWM technique, and explains the comparisons between HEPWM \& PSPWM [22]-[24]. The objective of this article is harmonic elimination [25]. By using multilevel voltage source inverter only non triplent harmonic components are considered for the elimination because, triplent harmonics are reduces the internal harmonics reduces line to line voltages to solve 11HEPWM switching angles can be performed by using DE algorithm that is synthesised to 23 level cascaded multi level VSI by using these higher levels of multilevel VSI. The output voltage will increase. So that there is no need to use step up transformers to boost output voltage. Advantages of HEPWM are

a. Wide modulation index.

b. Small in step size.

c. THD values are below $5 \%$.

d. Improves output voltage.

e. Superior harmonic spectra \& lower switching losses so fixed switching frequency can reduce the size of coupling inductor.

The Figure 4 shows the harmonic elimination using PWM technique. To eliminate harmonics in the given system must depends on proper exchange of reactive power and efficient control of DSTATCOM [26] to achieve this two approaches are present direct \& indirect control [27]. In this control technique main concentration is on phase angle of VSI $(\delta) \&$ modulation Index $(\mathrm{M})$, here phase angle is control variable and modulation is treated as a constant at maximum value of modulation index.

Switching angles of each H-bridge are generated based on comparison between low frequency reference signal modulations with high frequency triangular carrier signal. The Required switching angles are pre computed by solving the equations stored in the memory whenever the requirement of wave construction it fetch from memory. Mainly controller divided into three parts. They are, a) Generation of d-q current b) Inner current control and c) PWM generation [28], [29]

In this controller, mainly consists of phase locked loop along with dq park transformation. It is used to convert time varying parameters into dc quantities from the point of common coupling extract variables of voltage \& current, these are giving input to the park transformation, here those quantities are converted into dc quantities in order to generate proportional integral signals [30]. One of the input is from park transformation output and other one is from extracted dc parameters at VSI with this controller generates proper $\mathrm{V}_{\mathrm{cd}}{ }^{*}, \mathrm{~V}_{\mathrm{cq}}{ }^{*}$ are convert into $\mathrm{M}, \delta$ are given as input to the PWM generator. In the given system these $\mathrm{M}$ value are pre calculated by using DE approach where as $\delta$ value are retrieved from the tables. Depends on the values of $\mathrm{M}$ offered by controller. Output voltage of grid is synchronized with the help of PLL.

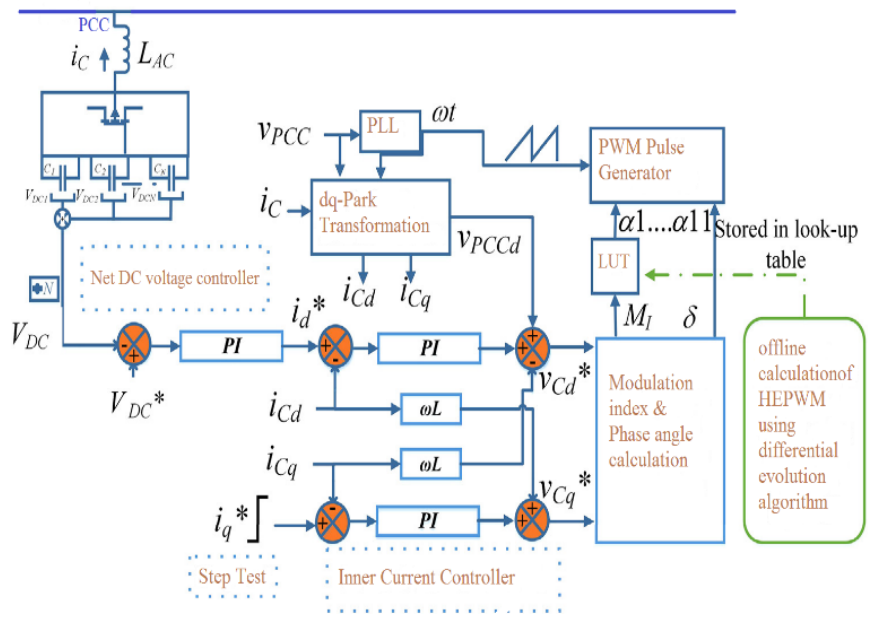

Figure 4. Harmonic elimination using PWM technique 


\subsection{Recursive least square (RLS) harmonic estimation technique}

In 2018 Bhimsingh [31] proposed maximum power point tracking technique to a three phase system to enhance power quality and support the three phase AC grid by supplying power both to the grid and the connected loads. In 2015 Priyabrat garanayak, Gayadhar Panda, Pravat Kumar Ray [32] illustrated harmonic estimation using RLS algorithm and elimination with improved current control technique based SAPF in a distribution network [33], [34]. In this paper explained about recursive least square harmonic estimation technique, in this amplitude and phase angle of basic fundamental harmonics is performed. Advantages of RLS are,

a. With this computation is Easy.

b. Accuracy is good.

c. Good convergence.

d. Tracking time less.

e. Power factor is nearly unity.

RLS technique is used to generate pulses or commands to turn on the voltage source inverter based on two approaches like a) Frequency domain approach and b) Time domain approach.

In case of frequency domain approach signals will generate by using Fourier method or kalmon filtering method, in time domain approach [35], [36] to generate pulses may divided into

a. Instantaneous P-Q theory.

b. Synchronous d-q reference frame theory.

c. Notch filters or PI controllers.

RLS technique is used for estimator, from the AC bus noisy harmonic signals are collected and these are treated as a test signals. This algorithm is applicable for two times, one is source current without and with shunt active power filters to generate reference signals for switching operation. Shunt active power filter is designed to convert fixed abc to rotating dq frame and in this case low pass filters also used to reduce the harmonics in nonlinear current and also for better performance of shunt active power filter improved current controlled techniques also used for distribution side by using RLS technique [37], [38] estimate dominant harmonics of supply side current and also estimate fundamental phase angle and amplitude.

\subsection{An artificial intelligence based controller}

In 2014 Vasundhara Mahajan, Pramod Agarwal, Hari Om Guptha proposed [39] An Artificial intelligence based controller for multilevel harmonics filter. In this artificial intelligence based controller is used for harmonic compensation and dc voltage regulation. This theory is used to develop and estimate the reference current by this better performance will observed [40]. Advantages are,

a. Fast responding time.

b. Easy and quick estimation of Fourier analysis.

c. Doesn't require any mathematical model.

d. Repetitive training and self adjusting capability.

In this case consider harmonic filters have five level cascaded H-bridge multilevel inverter and artificial intelligence based controller used. This controller is combination of Fuzzy logic controller [41], ANN current controller and FSPWM. In this scheme instantaneous power theory is implemented and reference component is considered by using ANN and after this approach is uses two different fuzzy logic controllers. In that one is for reducing dc voltage and second one is producing gate pulses for the IGBT inverter.

The Figure 5 shows the bock diagram for Artificial Intelligence based controller. The ANN is having capability as fast as compared with other controllers. To get the reference signals Instantaneous power theory is used for generate current reference signals, Fuzzy Logic controller is used for multilevel inverter to control voltage and currents. In Fuzzy logic controller, the main function is voltage regulation and other one is filter current errors can adjustable. These can be done by few steps as given below.

a. Initially recognisation of inputs and output parameters then formulation of control rules possibilities from association functions and control rules.

b. Possibilities from association functions and control rules then convert fuzzy sets into crisp sets then after tuning of gains for desired performance.

c. With this controller can achieved source current harmonics of $2 \%$ for increasing RL load and $2.53 \%$ for RC Loads. With can achieve fast convergence and minimization of DC voltage ripples but variation in time w.r.t loading parameters completed. 


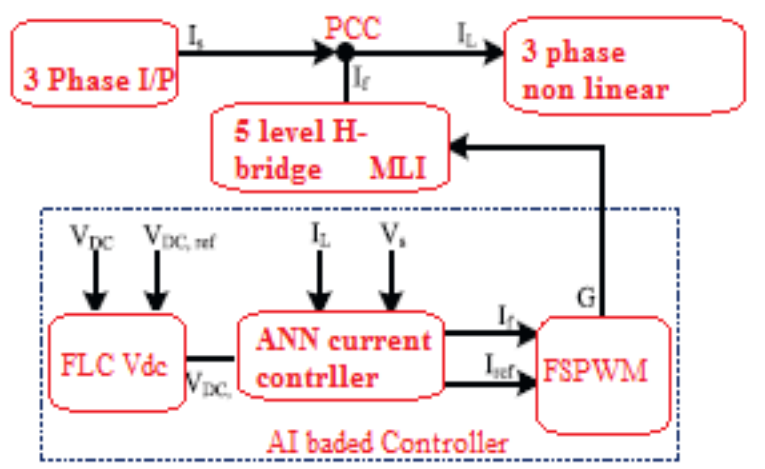

Figure 5. Block diagram for artificial intelligence based controller

\subsection{Adaptive leaky least mean square technique}

In 2017 Moushumi Patowary, Gayadhar Panda, Bimal C. Deka [42] Illustrated "An Adaptive current control-detuned harmonics elimination schemes for enhancement of power quality in RES interfaced AC-grid network".

The aim of this paper is to reduce the reactive power load balancing and elimination of harmonics. Which are taken care by using neural network identified adaptive leaky least mean square technique. The controller can analyzed with the help of RES interfaced grid tied system, system consists of VSI, and it converts electrical power from dc to ac. In order to control this VSI mainly two types of approaches are there, one is outer loop control and the other one is inner loop control. In outer loop control method voltage is controlled by using convention proportional controller.

Where as inner loop control consists of Neural Network identified ALLMS technique is used to make active and reactive power components independent of each other control algorithm along with updating of wait vectors are helpful to generate phase current reference signals. Two control loops are important to mitigate current harmonics disturbances, smooth set point voltage tracking, ALLMS along with detuned LC filter will acts like harmonic mitigation as well as power factor rectifier [43], [44].

This technique is to provide requirements of load with in very short time interval and power quality is preserved by maintaining \%THD within the limits. It offers accurate and faster control and provides robust performance but possibilities for heating of supply cables. Figure 6 gives the Block diagram for Adaptive Leaky Least Mean Square Technique.

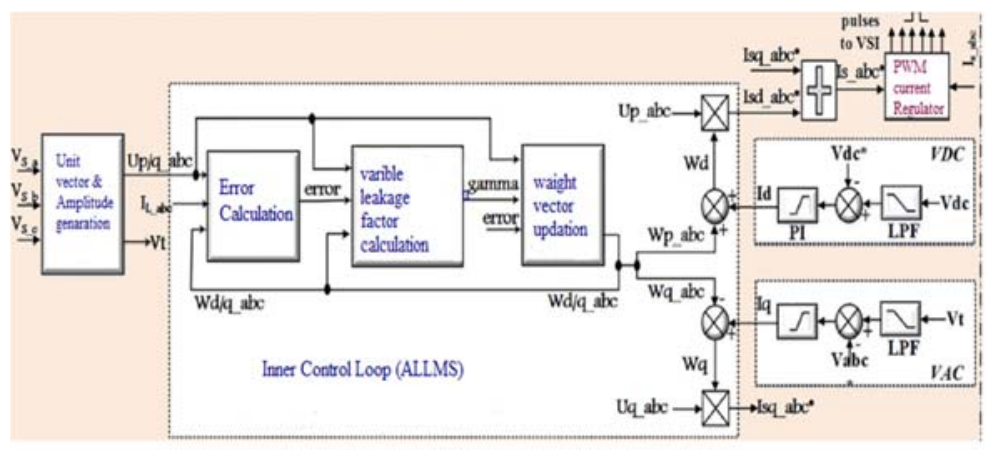

Figure 6. Block diagram for adaptive leaky least mean square technique

\subsection{Neuro fuzzy controller}

In 2017 Hakan Acikaz, Faith kecerlogler, Ahmed gani proposed by [45] Improved control configuration of PWM rectifier based Neuro Fuzzy controller.In this paper author explained about neuro fuzzy controller. Generally rectifiers are used to convert ac/dc. Many control techniques are proposed in 
order to improve the performance of rectifier. One of the most popular and regular rectifier type is PWM based rectifier, with the help of this can achieve lower input current harmonics and high power factor. In this study three neuro fuzzy controllers are used in suggested PWM rectifier along with dq axis currents also controllable. These controllers are based on combination of execution of functions of fuzzy controllers by ANN constructively. Advantages of NFC are,

a. These are robust in structure.

b. It is having non linear structure.

c. Not require mathematical model.

Here Sugeno one of the fuzzy rule is used and NFC is having two inputs, one output and six layers, and one for each input five member ship functions are changes In this control technique two units of NFCs are used one for to control of dc bus voltage and other to control dq axis current [46]. As an inputs of NFCs error and changes of reactive and active current these are used for dq axis current control, rectifier generates the change of voltage in both dq axis components are obtained from output of NFCs these are used in dq axis current controls. Figure.7 gives the block diagram of ANN.

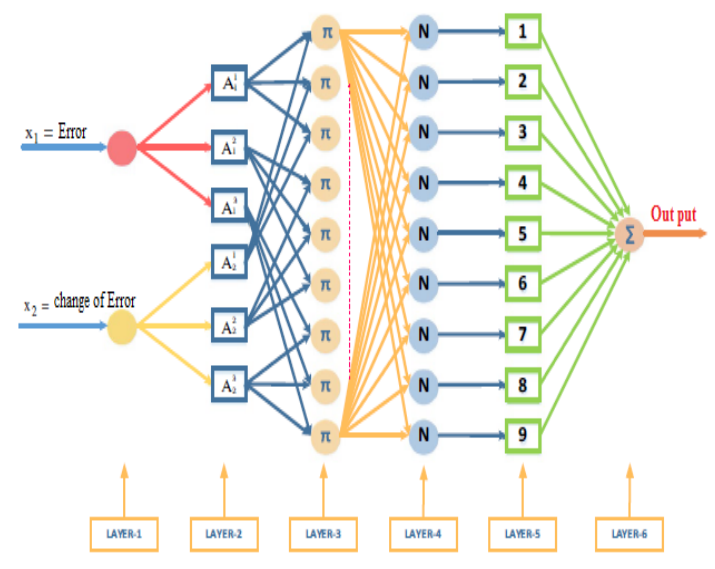

Figure 7. Block diagram of ANN

\section{CONCLUSION}

This paper presents Comprehensive review on distribution system and power quality problems. In this survey mainly concentrate on different types of control techniques of DSTATCOM. The basic control techniques are Synchronous Reference Frame theory, Instantaneous Reactive power component theory, Symmetrical component theory these control strategies are reviewed with the help of basic control techniques power quality problems will be evaluated. In this paper novel control techniques are Recursive least square method, phase shift pulse width modulation method, Fuzzy Logic Controller, Neural Network method, Neuro Fuzzy controllers are reviewed. For better performance of DSTATCOM and problems in a distribution side also resolved by these techniques.

The future work of this article is higher levels of multilevel inverter can consider to obtain better results of switching devices, use of other multilevel inverter topology to improve performance of system. By using different new control strategies improve the power quality and also reduce the harmonic distortion.

\section{REFERENCES}

[1] X Madhu B. R.1, Dinesh M. N.2, Ravitheja B. M.,"Design of Shunt Hybrid Active Power Filter to Reduce Harmonics on AC Side Due to Non-linear Loads," International Journal of Power Electronics and Drive System (IJEDS), vol. 9(4), pp. 1926-1936, ISSN. 2088-8694, Dec 2018.

[2] Bachar Rahimap, Golea Amar, Benchouia Mohamed Toufik, Chebaani Mohamed, "High-performance active power filter implementation based on predictive current control," International Journal of Power Electronics and Drive System (IJPEDS), vol. 10(1), pp. 277-287,ISSN. 2088-8694, March 2019.

[3] CH. Sri Prakash1, G. Kesava Rao2, O. Chandrasekhar3, P. V. Satyaramesh, "A Novel Multi-Functional DSTATCOM with Distribution Generation using FRC Controller," International Journal of Power Electronics and Drive System (IJPEDS), vol. 8(3), June 2018, pp. 1373-1382 ISSN. 2088-8708 December 2018, 
[4] Ankur gheewala, Nimesh nagar, "A Review on Different control algorithm of DSTATCOM," In Shroff S R Rotary Institute of Chemical Technology, India, 2017.

[5] R.Geetha and M.aishwariya devi, "Various control techniques for powerquality improvement using DSTATCOM," International Journal of power control signal and computation, Jun 2012.

[6] Preeti Pauline Mary and Sivachidambaranathan.V, "Design of New Bi-Directional Three Phase Parallel Resonant High Frequency AC Link Converter," International Journal of Applied Engineering Research, vol 10(4), PP 8453-8468, ISSN. 0973-4562, 2015.

[7] Kavitha.M and Sivachidambaranathan.V, "Performance Analysis of Transformer-Less Two Phase Interleaved High Gain DC Converter using MPPT Algorithm," Indian Journal of Science and Technology, vol 8(15), ISSN. 09746846, 61428, pp 1-8, July 2015.

[8] M.Preeti Pauline Mary and V.Sivachidambaranathan, "Enhancement of Active Power Filter Operational Performance using SRF Theory for Renewable Source," Indian Journal of Science and Technology, ISSN. 09746846, vol. 8 (21), pp. 71562, September 2015.

[9] Kavitha.M and Sivachidambaranathan.V., "Comparison of Different Control Techniques for Interleaved DC-DC Converter," International Journal of Power Electronics and Drive System (IJPEDS), ISSN. 2088-8694, vol. 9(2), , pp. 641-647, June 2018

[10] Sivachidambaranathan.V, S.S. Dash and M.Santhosh Rani, "Implementation of Half Bridge DC to DC Converter using Series Resonant Topology," European Journal Scientific Research, ISSN. 1450 - 216X, vol.74(3), pp 381-388Apr 2012.

[11] M.George, K. P. Basu, "Three-Phase Shunt Active Power Filter," American Journal of Applied Sciences, vol. 5(8), pp. 909-916, 2008

[12] A. Ajami and S. H. Hosseini, "Implementation of a Novel Control Strategy for Shunt Active Filter," ECTI TRANSACTIONS ON ELECTRICAL ENG., ELECTRONICS, AND COMMUNICATIONS,” vol.4(1), pp. 40-46, February 2006.

[13] P. Zanchetta, M. Sumner, M. Marinelli and F. Cupertino, "Experimental modeling and control design of shunt active power filters," Control Engineering Practice, vol.17, pp. 1126- 1135, May 2009.

[14] M. Ghandchi, A. Ajami and M. Moeini, "A Simple and Low Cost Control Strategy for Multilevel Shunt Active Filters," in Proceeding of International Conference on Control, Automation and Systems 2008 in COEX, pp. 14-17, Seoul, Korea, October 2008.

[15] Moh. Jauhari, Dedet Candra Riawan, Mochamad Ashari, "Control Design for Shunt Active Power Filter Based on p-q Theory in Photovoltaic Grid-Connected System," International Journal of Power Electronics and Drive System (IJPEDS), vol. 9(3), pp. 1064-1071 ISSN. 2088-8694, September 2018.

[16] Izhar, M, Hadzer, "Performance for passive and active power filter in reducing harmonics in the distribution system," Power and Energy Conference, pp.104-108, 2004.

[17] Shin-Kuan Chen, 'A new instantaneous power theory-based three phase active power filter," Power Engineering Society Winter Meeting, vol. 4, pp. 2687-2692, 2000.

[18] Qirong Jiang, Dongyuan Zhao, Jianye Chen,"Active Power Filter- Design. Elementary. Control [M]," Science Press, Beijing 2005.

[19] A. Awalludin, C. L. Toh, "Harmonic Mitigation in Traction Supply Substation Using Cascaded H-Bridge Converter," International Journal of Power Electronics and Drive System (IJPEDS), vol. 9(4), pp. 1745-1754 ISSN. 2088-8694, Dec 2018.

[20] R. Shibarani, Dr. C. Srinavas Rao, Dr. M. Vijaya Kumar, "PSPWM based five level shunt active filter for power quality improvement in power System network," 1st international conference on power engineering at VIT university, Chennai, Mar 2017.

[21] Ahmed Majed, Zainal Salam and Abdul Moeed Amjad, "Harmonics elimination PWM based direct control for 23levelmultilevel distribution STATCOM using differential evolutionalgorithm," Electric Power Systems Research, vol. 152, pp. 48-60, 2017.

[22] B. Gultekin, M. Ermis, "Cascaded multilevel converter-based transmissionSTATCOM: system design methodology and development of a12 kV 12 MVAr power stage," IEEE Trans. Power Electron, vol. 28 pp. 4930-4950, 2013.

[23] M. S. A. Dahidah, G. Konstantinou, V. G. Agelidis, "A review of multilevelselective harmonic elimination PWM: formulations, solving algorithms,implementation and applications," IEEE Trans. Power Electron, vol. 30, pp. 4091-4106, 2015.

[24] J. I. Leon, S. Kouro, L. G. Franquelo, J. Rodriguez, B. Wu, "The essential role andthe continuous evolution of modulation techniques for voltage-sourceinverters in the past, present, and future power electronics," IEEE Trans. Ind.Electron. vol. 63, pp. 2688-2701, 2016.

[25] G. Konstantinou, V. Agelidis, "On re-examining symmetry of two-levelselective harmonic elimination PWM: novel formulations, solutions andperformance evaluation," Electr. Power Syst. Res, vol. 108, pp. 185-197, 2014.

[26] S. K. Patel, S. R. Arya, R. Maurya, B. Singh, "Interior point algorithm for optimalcontrol of distribution static compensator under distorted supply voltageconditions," IET Gener. Transm. Distrib, vol. 10, pp. 1778-1791, 2016.

[27] B. S. Chen, Y. Y. Hsu, "A minimal harmonic controller for a STATCOM," IEEETrans. Ind. Electron, vol.55, pp. $655-664,2008$.

[28] C. Schauder, H. Mehta, "Vector analysis and control of advanced static VARcompensators," IEE Proceedings C (Generation, Transmission and Distribution), pp. 299-306, 1993.

[29] B. Singh, R. Saha, A. Chandra, K. Al-Haddad, "Static synchronous compensators(STATCOM): a review," IET Power Electron, vol. 2, pp. 297-324, 2009.

Int J Pow Elec \& Dri Syst, Vol. 10, No. 2, June 2019 : $813-821$ 
[30] A. Balikci, E. Akpinar, "A multilevel converter with reduced number of switchesin STATCOM for load balancing," Electr. Power Syst. Res, vol. 123, pp. 164-1731, 2015.

[31] Bhim singh, "Control of Grid Tied Smart PV-DSTATCOM System Using an Adaptive Technique," IEEE transactions, vol. 9(5).

[32] priyabarath, Garanayak, "Harmonic estimation using RLS algoritham and elimaination with improved current cintroll techniqures SAPF in distribution network," vol. 73, pp. 209-217.

[33] Dash PK, Swain DP, Liew AC, Rahman S., "An adaptive linear combiner for online tracking of power system harmonics," IEEE Trans Power Syst Harmonics, vol. 11(4), pp. 1730-5, 1996.

[34] Kennedy K, Lightbody G, Yacamini R. "Power system harmonic analysis using the Kalman filter," IEEE Power Eng Soc Gen Meet, vol. 2, pp. 752, 2003.

[35] Jiang J, Zhang Y.,"A revisit to block and recursive least squares for parameterestimation," Comput Electr Eng, vol. 30, pp. 403-16, 2004.

[36] Bettayed M, Qidai U.,"Recursive estimation of power system harmonics," Electr Power Syst Res, vol. 47, pp. 143-52, 1998.

[37] Akagi H., "Active harmonic filters," Proc IEEE, vol. 93(12), pp. 2128-41, 2005.

[38] Singh B, Al-Haddad K, Chandra A., "A review of active power filters for power quality improvement," IEEE Trans Industr Electron, vol. 46(5), pp. 960-71, 1999.

[39] Vasundhara maharajan, Pramod agarwal, "An artificial intelligence based controller for multilevel harmonic filter," vol. 58 , pp. 170-180.

[40] Kazmierkowski MP., "Neural networks and fuzzy logic control in powerelectronics. Selected problems control in power, electronics," Academic Press, pp. 351, 2002.

[41] Zadeh LA, Klir GJ, Yuan B,. "Fuzzy sets fuzzy logic, and fuzzy systems:Selected papers," World Scientific Publishing Company Incorporated, 1996.

[42] Moushumi Patowary, Gayadhar Panda and Bimal C. Deka, "An adaptive current control-detuned harmonics elimination schemes for enhancement of power quality in RES interfaced AC-grid network," Sustainable Energy Technologies and Assessments, vol. 25, pp. 11-23, 2018.

[43] Subudhi B, Ray PK, Ghosh S., "Variable leaky least mean-square algorithm-basedpower system frequency estimation," IET Sci Meas Technol, vol. 6(4), pp. 288- 97, 2012.

[44] Kamenetsky M, Widrow B., "A variable leaky LMS adaptive algorithm. Signals, Systems and Computers, 2004," Conference Record of the Thirty-Eighth AsilomarConference, vol. 1, pp. 125-128, Nov 2008.

[45] Hakan acikgoz,O. Fatith kececioglu, "Improved control configuration of PWM rectifiers based onneuro-fuzzy controller," Acikgoz et al, Springerplus, 2016.

[46] Mohagheghi S, Venayagamoorthy GK, Harley RG, "Optimal neuro-fuzzy external controller for a STATCOM in the 12-bus benchmark power system," IEEE Trans Power Deliv, vol. 22, pp. 2548-2558, 2007. 